\title{
Bone regeneration in cranioplasty and clinical complications in rabbits with alloxan-induced diabetes
}

Evanice Menezes Marçal Vieira ${ }^{(a)}$ Camila Satie Ferreira Ueno ${ }^{(b)}$ Vivian Neves Valva ${ }^{(c)}$ Maria das Graças Vilela Goulart(d) Terezinha de Oliveira Nogueira ${ }^{(e)}$ Mônica Fernandes Gomes ${ }^{(f)}$

(a) Graduate Student, Oral Biopathology Program, School of Dentistry of São José dos Campos, São Paulo State University (UNESP).

(b) Resident, Special Health Care Needs Association (ASPE); (c)Training Assistant; (d) Post-Doctoral Fellow (FAPESP);

(e) Associate Professor, Special Health Care Needs Association (ASPE); (f)Professor and Chairman, Special Health Care Needs Association (ASPE) - Bioscience Center for Special Health Care Needs (CEBAPE/ UNESP), School of Dentistry of São José dos Campos, São Paulo State University (UNESP).

\begin{abstract}
This research evaluated the bone repair process in surgical defects created on the parietal bones of diabetic rabbits using the guided bone regeneration technique to observe the effects of alloxan in the induction of diabetes mellitus. Twenty-four adult rabbits were divided into three study groups: control (C), diabetic (D) and diabetic associated to polytetrafluoroethylene (PTFE) membrane (D-PTFE). For diabetes induction the animals received one dose of monohydrated alloxan $(90 \mathrm{mg} /$ $\mathrm{kg}$ ) by intravenous administration in the auricular or femoral vein. In group D-PTFE the membrane covered both the floor and the surface of the bone defect. In groups D and C, the bone defect was filled up with blood clot. The specimens were fixed in $10 \%$ formol and prepared for histomorphometric analysis. The results showed that the $90 \mathrm{mg} / \mathrm{kg}$ dose of monohydrate alloxan was sufficient to promote diabetes mellitus when administered in the auricular vein. Bone regeneration was slower in the diabetic group when compared with the control and diabetic-PTFE groups, but there was no significant statistical difference between the two experimental groups (D and D-PTFE). The oral and general clinical complications among the diabetics were weight loss, polyuria, polyphagia and severe chronic gingivitis.
\end{abstract}

Descriptors: Diabetes mellitus; Bone regeneration; Diabetes complications; Alloxan.

\author{
Corresponding author: \\ Mônica Fernandes Gomes \\ Av. Eng. Francisco José Longo, 777 \\ São José dos Campos - SP - Brazil \\ CEP: 12245-000 \\ E-mail:mfgomes@fosjc.unesp.br
}

Received for publication on Jul 25, 2006

Accepted for publication on Jul 11,2007 


\section{Introduction}

Diabetes mellitus, a complex metabolic disorder, is a syndrome characterized by abnormalities in carbohydrate, lipid, and protein metabolism, that results either from a partial or an absolute insulin deficiency or from target tissue resistance to its cellular metabolic effects. ${ }^{1}$ This disease is characterized by the presence of few or by the absence of functional $\beta$ cells in the islets of Langerhans, and by a substantial reduction or inexistence of insulin secretion. ${ }^{2}$ According to literature, alloxan has been frequently used in rabbits to destroy the pancreatic beta cells and promote the disorganization of the pancreas parenchyma and consequently of its functions. The slower bone repair in diabetics is the consequence of a deficient function of osteoblasts, ${ }^{3}$ a diminished production of collagen ${ }^{4}$ and/or changes in the mineral metabolism. ${ }^{5}$ Therefore, the purpose of the present work was to establish an experimental model for alloxan-induced diabetes in rabbits, to evaluate qualitatively and quantitatively the bone repair process in surgical defects, and to investigate the general and oral clinical complications of this metabolic disease. ${ }^{6,7}$

\section{Material and Methods}

Twenty-four New Zealand adult rabbits with an average weight of $3.5 \mathrm{~kg}$ were divided into 3 groups: control (C), diabetic (D) and diabetic with PTFE barrier (D-PTFE). All animals received human care according to the National Research Council Criteria, and the study protocol was approved by the Committee for Animal Use, School of Dentistry of São José dos Campos, São Paulo State University (UNESP).

\section{Induction of Diabetes mellitus and blood glucose measurement}

Diabetes mellitus was induced in the rabbits by a single $90 \mathrm{mg} / \mathrm{kg}$ intravenous injection of the pancreatic $\beta$-cells toxin monohydrate alloxan (Sigma Aldrich Chemical - Saint Louis, MO, USA). The drug was dissolved in $5 \mathrm{ml}$ of $\mathrm{NaCl}(0.15 \mathrm{M})$ and immediately administered to the anesthetized rabbit via the marginal ear vein. For this study, a blood glucose level greater than $200 \mathrm{mg} / \mathrm{dl}$ was an indication of hyper- glycemia. NPH Human Insulin (Humulin ${ }^{\circledR}$ N-100, Eli Lilly do Brasil Ltda., São Paulo, SP, Brazil) was administered subcutaneously in order to maintain a stable serum glucose level between $200 \mathrm{mg} / \mathrm{dl}$ and $350 \mathrm{mg} / \mathrm{dl}$. The blood glucose level was monitored with a glucosemeter and by Onetouch Ultra test strips ${ }^{\circledR}$ (LifeScan Johnson \& Johnson, Milpitas, CA, USA) two times a day until sacrifice of the animals.

\section{Treatment protocol for surgical bone defect and postoperative phase}

The animals were anesthetized intramuscularly with $0.1 \mathrm{mg} / \mathrm{dl}$ of Rompum $^{\circledR}$ (Bayer, São Paulo, SP, Brazil) as a pre-anesthetic solution, and with $0.25 \mathrm{mg} / \mathrm{dl}$ of Ketalar $^{\circledR}$ (Aché Laboratórios Farmacêuticos S. A., Parke-Davis, Guarulhos, SP, Brazil) for complete anesthesia. An incision was made in the sagittal plane of the head, followed by muscular dissection, plane to plane, and incision of the periosteum. Subsequently, a surgical bone defect was created in each parietal bone with the aid of $8.0 \mathrm{~mm}$ trephine ${ }^{\circledR}$ (Titanium Fix, AS Technology, São José dos Campos, SP, Brazil). The bone defect had a circular form, with its depth equal to the thickness of the removed cortical bone. In group D-PTFE, the PTFE barrier was placed on the floor and on the surface of the surgical bone defect. Subsequently, the periosteum and the muscle were sutured as well as the skin. The animals were treated with $0.1 \mathrm{ml} / \mathrm{kg}$ of benzylpenicillin ${ }^{\circledR}$ (antibiotic, Pentabiótico; Fort Dodge Saúde Animal São Paulo, SP, Brazil) 24 hours before and 1 hour after surgery. Five days after surgery, $6 \mathrm{mg} / \mathrm{day} / \mathrm{kg}$ Celecoxib $^{\circledR}$ (Pfizer Pharmacia, São Paulo, SP, Brazil) was used as an anti-inflammatory. Fifteen, 30, 60 and 90 days after surgery, three animals of each group were sacrificed. The content of the bone defect was removed in block, fixed in 10\% formalin for 72 hours, decalcified in Plank-Rychlo solution and embedded in paraffin. The histological sections were $5 \mu \mathrm{m}$ thick and were stained with $\mathrm{H}-\mathrm{E}$.

\section{Statistical and histomorphometric analysis}

The histomorphometric method determines the 3-dimensional quantitative parameters of anatomical structures in the histological sections. It is ab- 
solutely necessary to randomly separate every step of the experiment, such as: selection of animals and blocks, histological sections and fields. Moreover, the minimal number of histological sections for this analysis is obtained by the Cumulative Frequency Method, which is characterized by the empirical determination of a minimum number of observations, in order to build an adequate measurement sample. ${ }^{8,9}$ In this research, a Zeiss II reticule was placed over a Zeiss microscope with $10 \mathrm{X}$ ocular compensation (W-PI, Carl Zeiss, Germany) to evaluate the bone density (Bd). The reticule image was superimposed on the desired histological fields. The reticule points $(\mathrm{Ni})$ and the total number of points over the bone defect $(\mathrm{N})$ were counted. The bone density was evaluated with the following formula:

$$
\mathrm{Bd}=\frac{\mathrm{Ni}}{\mathrm{N}}
$$

where:

$\mathrm{Ni}$ : number of points in bone trabeculae;

$\mathrm{N}$ : total number of points over bone defects.

The chosen bone defect was submitted to examination with serial microscopic sections, from which approximately 100 sections were obtained. From these sections, 4 were randomly chosen for histomorphometric analysis. Subsequently, eight histological fields from each section of the surgical bone defect region were analyzed. For this step, a $20 \mathrm{X}$ objective (A-Plan, Carl Zeiss, Germany) and a 10 X ocular (WPI, Carl Zeiss, Germany) of an optical microscope (Axioskop 40, Carl Zeiss, Germany) were used. The objective showed a 100-point reticule corresponding to $7840 \mu^{2}$ for measuring the bone tissue area. The histomorphometric results were submitted to analysis of variance (ANOVA) and to Tukey test with the aid of the GraphPad InStat software version 3.00 for Windows 95 (GraphPad Software, San Diego, CA, USA). The level of significance used was $\mathrm{p}<0.05$.

\section{Results}

\section{Effects of alloxan in the pancreas and clinical complications of Diabetes mellitus}

After alloxan administration, the pancreas of the diabetic animals were removed and analyzed micro- scopically to check the effects of the drug. The microscopic sections showed parenchyma disorganization with presence of atypical acinar cells, scarce secretion vesicles, atrophy and a decreased number of Langerhans islets in some regions. In this study, the general clinical complications in the diabetic rabbits were weight loss (24/24), polyuria (24/24), polyphagia (24/24), ketoacidosis, accentuated hypoglycemia (2/24), convulsions, heart attack, diabetic foot $(1 / 24)$, acute dermatitis $(1 / 24)$, eritematous and ulcerated lesion associated to fungal and bacterial infections, located in the submandibular region extending to trunk and neck regions, and intracranial abscess $(5 / 24)$ in the region of the surgical defect. The intraoral examination revealed severe chronic gingivitis (11/24) (Figure 1).

\section{Microscopic features}

15 days

The histological sections of the control group (group C) showed the bone defect filled with osteogenic connective tissue and with discrete and immature bone trabeculae. The connective tissue was mainly constituted by osteoprogenitor cells and collagen fibers as well as by few mononuclear inflammatory cells. The immature bone trabeculae were full of delicate and irregular cells localized in the periphery of the bone defect growing into its central portion. Some histological sections also showed muscle and adipose tissue in the bone defect area (Figure 2A). In group $\mathrm{D}$, the same microscopical features of the control group were observed. There was a very thin strip of newly formed bone when compared to the original cortical bone (Figure 2B). In group D-PTFE, the histological features were the same as described before for both previous groups. However, there were numerous newly formed bone trabeculae when compared with group D. There were areas of interstitial hemorrhage and some mononuclear inflammatory cells. There was a strip of bone tissue in the defect as thick as the original cortical bone (Figure 2C).

\section{0 days}

The bone defects in group $\mathrm{C}$ were filled by mature and thick bone trabeculae at the periphery of the defect and immature trabeculae in the central 


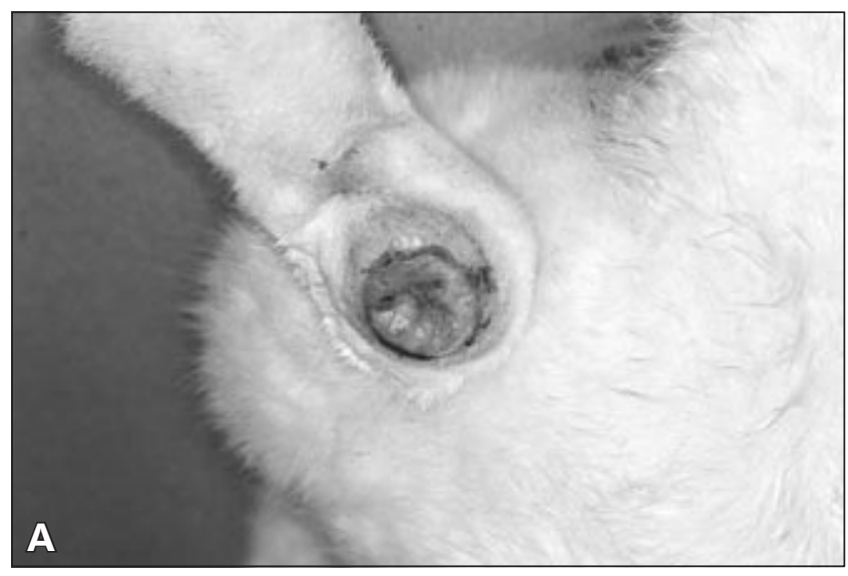

Figure 1 - Oral and general clinical complications of diabetes mellitus: diabetic foot $(\mathbf{A})$ and chronic gingivitis (B) in the region of the inferior central incisors.

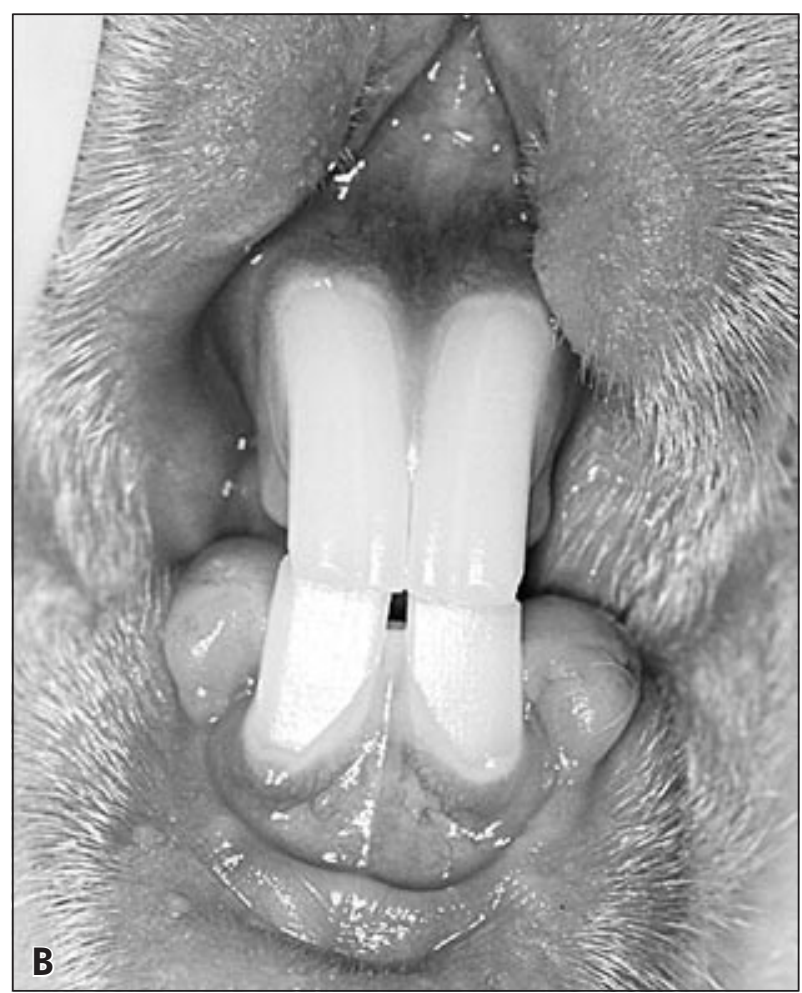

of the defect, and the strip of newly formed bone tissue was as thick as the original cortical bone.

\section{0 days}

In group $\mathrm{C}$ the bone defect was filled with mature bone tissue regularly distributed, but there were still some connective osteogenic tissue. The newly formed bone exhibited Havers channels and the bone growth inside the defect was still centripetal with some osteoclastic cells starting bone remodeling. The strip of newly formed bone tissue had a thickness similar to that of the original cortical bone. In group D, connective osteogenic tissue and discrete bone trabeculae were still found in the bone defect. This tissue was disorganized and the collagen fibers were irregularly distributed. The amount of bone tissue was lesser when compared with groups C and D-PTFE. In some sections there was invasion of muscle and adipose tissue in the interior of the defect. In group D-PTFE the defect was filled with bone tissue and disorganized connective osteogenic tissue. The bone trabeculae were mature in the periphery and immature in the central por- 

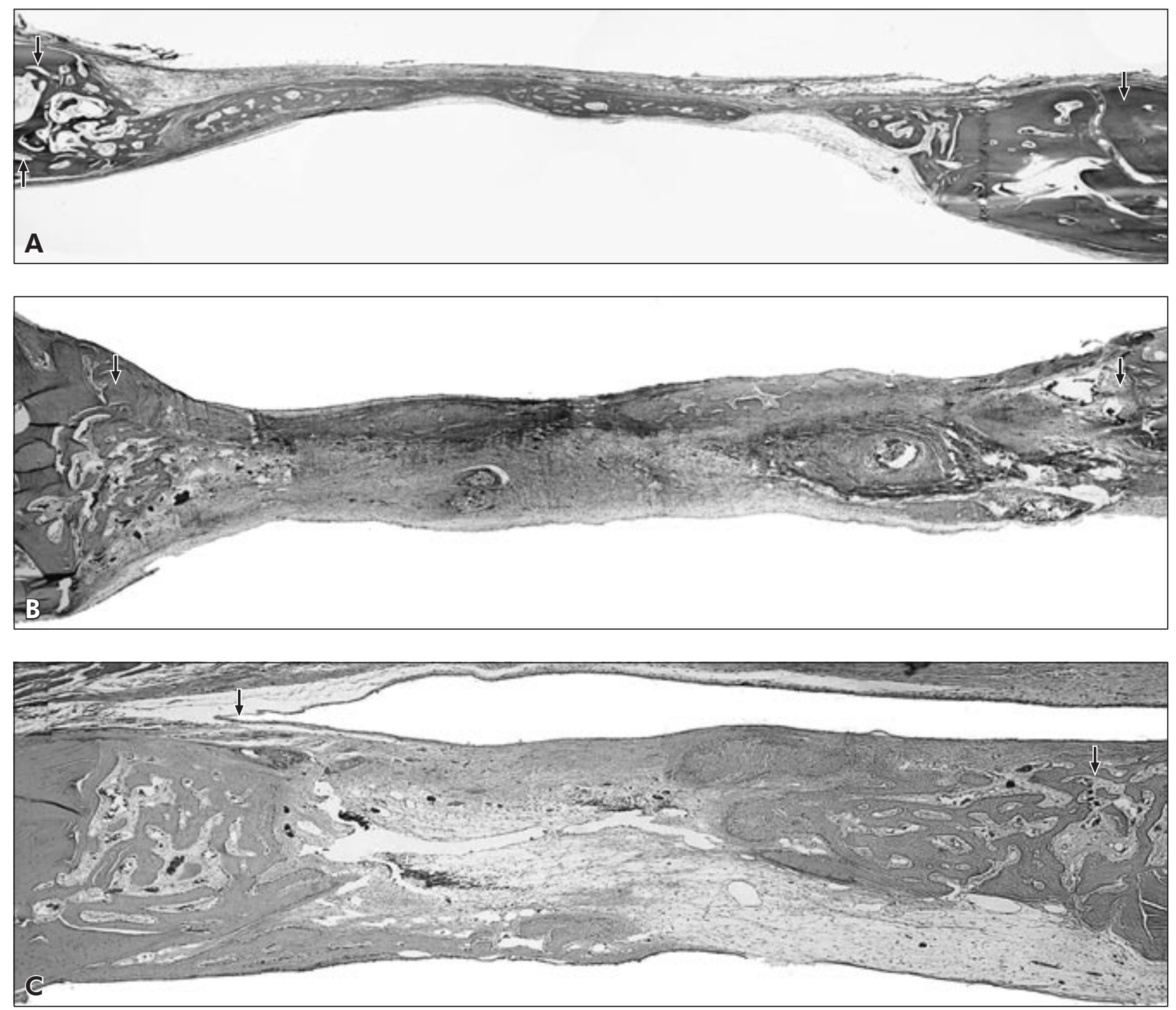

Figure 2 - Photomicrographs of the bone defect after 15 days. Limits of the surgical bone defect are indicated by arrows: (A) control; (B) diabetic; (C) D-PTFE ( $\mathrm{H}$-E, original magnification $50 \mathrm{X})$.

tion. The trabeculae were homogenous, regularly distributed and occupied the space left by the PTFE barrier. The strip of bone tissue at the periphery of the bone defect was as thick as the original cortical bone.

\section{0 days}

In group $\mathrm{C}$, the bone defect was filled by mature bone tissue and in some areas there was an amount of fibrous connective tissue that was not calcified anyway forming a kind of fibrous capsule that was relatively thick, although some very insignificant newly formed bone trabeculae were permeating some areas (Figure 3A). In group D, there was fibrous connective tissue in the bone defect permeated by small thin, irregular and mature bone trabeculae. At the periphery, mature bone tissue could be seen growing towards the center of the bone defect. The control group revealed very few Havers systems. In all sections of these groups, there was an undesirable kind of tissue (Figure 3B). In group D-PTFE the bone defect was filled by mature bone trabeculae with a regular feature, but there was also fibrous connective tissue as well as osteogenic connective 

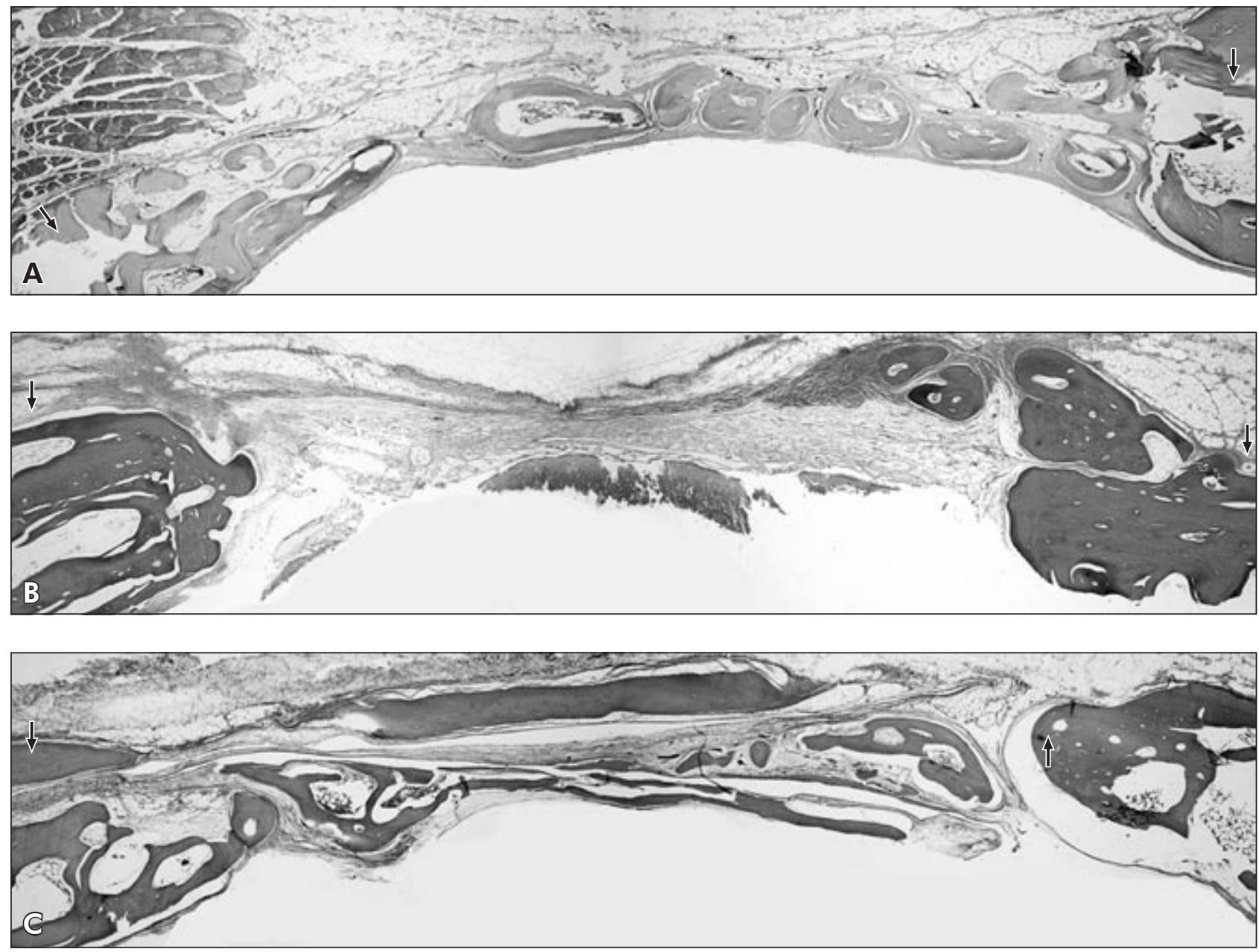

Figure 3 - Photomicrographs of the surgical defect region after 90 days. Limits of the surgical bone defect are indicated by arrows: (A) control; (B) diabetic; (C) D-PTFE (H-E, original magnification $50 \mathrm{X})$.

tissue; the cortical bone was preserved in all sections observed. The bone marrow spaces were very large with red bone marrow. The PTFE barrier was dislocated in some histological sections examined. The quality of bone tissue was well organized with thick bone trabeculae regularly and uniformly distributed in the field of the bone defect (Figure 3C).

\section{Histomorphometric and statistical analysis}

The histomorphometric analysis aimed at measuring the volume density of the newly formed bone matrix in the bone defects of groups C, D and D-PTFE, as well as providing the necessary data for the statistical analysis of these measurements. The mean values and standard deviations
Table 1 - Density of newly formed bone tissue of the studied groups after the observation periods (Mean \pm SD).

\begin{tabular}{l|c|c|c}
\hline \multicolumn{1}{c|}{ Periods } & Control & Diabetic & Diabetic-PTFE \\
\hline 15 & $31.66 \pm 2.47$ & $18.48 \pm 4.84$ & $17.60 \pm 0.20$ \\
\hline 30 & $39.96 \pm 0.43$ & $30.43 \pm 15.06$ & $36.70 \pm 4.10$ \\
\hline 60 & $45.60 \pm 4.09$ & $36.44 \pm 7.93$ & $32.74 \pm 0.92$ \\
\hline 90 & $53.24 \pm 5.09$ & $44.10 \pm 17.52$ & $51.93 \pm 1.20$ \\
\hline
\end{tabular}

The results were not statistically significant between groups $D$ and D-PTFE $(p>0.05)$.

of the bone defect histomorphometry of the control (C), diabetic (D) and Diabetic-PTFE (DPTFE) groups for the different periods are shown in Table 1. 


\section{Discussion}

For our study we chose alloxan to produce experimental diabetes mellitus because of its efficient selective cytotoxic action on $\beta$-cells of the pancreas Langerhans islets. ${ }^{10}$ In this study, for all periods of observation of the control group, the mean bone density increased gradually and progressively. Simion et al. ${ }^{7}$ (1994) compared clinical, microbiologic and morphostructural aspects of the healing process with PTFE membranes, placed in fresh extraction dental sockets, which did or did not show early membrane exposure. The membranes are highly biocompatible and did not interfere with the healing process. The PTFE barrier promoted an osteoconductive property, which positively aided the bone repair process in this experimental study as well as in those of Gomes et al. ${ }^{6}$ (2002) and Carvalho et al. ${ }^{8}$ (2004), whose results were already described. Previously, however, a relevant fact in all specimens of the diabetic group was the discrepant variation in bone density, especially thirty and sixty days after surgery, that had decreased significantly. Studies of Alkan et al. ${ }^{11}$ (2002) did not find good results using doxycicline in the healing of bone defects in experimental diabetes mellitus. This study found that administration of doxycicline did not significantly alter the amount of bone formation during the healing process of bone defects in control and in diabetic rats. The work of Grandini $^{9}$ (1978), an histologic study of the effects of diabetes on wound healing of dental sockets in diabetic rats, observed a delayed healing of bone regeneration after partial pancreatectomy, caused by metabolic modification of the induced disease. Diabetes mellitus can be induced also by streptozotocin administered chronically. ${ }^{4}$ The purpose of the study was to correct abnormal bone and mineral metabolism. It was concluded that prolonged streptozotocin-induced diabetes mellitus in rats resulted in reduced bone turnover and growth arrest, which

\section{References}

1. Vernillo AT. Diabetes mellitus: Relevance to dental treatment. Oral Surg Oral Med Oral Pathol Oral Radiol Endod. 2001;91(3):263-70. are completely corrected by insulin therapy. Many of the chronic diabetes mellitus involve defects in the connective tissue such as poor wound healing and diminishing bone formation, because collagen is the major protein component of those connective tissues. A production of collagen has been examined in diabetic rats using tritiated proline. It was concluded that diabetes is associated with a marked decrease in collagen production. Rico et al. ${ }^{3}$ (1989) considered that the mechanism for underlying diabetic osteopenia is still unclear and may involve osteoblastic activity, and their results suggest that deficient osteoblast function could be responsible for osteopenia in diabetics. For He et al. ${ }^{12}$ (2004), diabetes decreases osteoclastogenesis, reduces bone formation and enhances apoptosis of osteoblastic cells in bacteria stimulated bone loss. They affirm that diabetes may cause a net loss of bone because the suppression of bone formation is greater than the suppression of bone resorption.

Our clinical results showed weight loss, polyuria and polyphagia and severe chronic gingivitis, in accordance with the results of Grandini ${ }^{9}$ (1978) and Hough et al. ${ }^{5}$ (1981).

\section{Conclusion}

This research work showed that $90 \mathrm{mg} / \mathrm{kg}$ of monohydrate alloxan was sufficient to promote diabetes mellitus experimentally when administered in the auricular vein. The bone repair was slower in the diabetic group when compared with the control and diabetic-PTFE groups, but there was no significant statistical difference between these two experimental groups (D and D-PTFE). The oral and general clinical complications were accentuated weight loss, polyuria, polyphagia and severe chronic gingivitis.

\section{Acknowledgements}

The authors are grateful to the Quaglia Laboratory, São José dos Campos, SP, Brazil.

2. Guyton AC, Hall JE. Insulin, Glucagon, and Diabetes mellitus. In: Guyton AC, Hall JE. Textbook of Medical Physiology. $10^{\text {th }}$ ed. Philadelphia: Elsevier; 2000. p. 827-40. 
3. Rico H, Hernandez ER, Cabranes JA, Gomez-Castresana F. Suggestion of a deficient osteoblastic function in diabetes mellitus: the possible cause of osteopenia in diabetics. Calcif Tissue Int. 1989;45(2):71-3.

4. Spanheimer RG, Umpierrez GE, Stumpf V. Decreased collagen production in diabetic rats. Diabetes. 1988;37(4):371-6.

5. Hough S, Avioli LV, Bergfeld MA, Fallon MD, Slatopolsky E, Teitelbaum SL. Correction of abnormal bone and mineral metabolism in chronic streptozotocin-induced diabetes mellitus in the rat by insulin therapy. Endocrinol. 1981;108(6):2228-34.

6. Gomes MF, dos Anjos MJ, Nogueira T de O, Catanzaro-Guimarães SA. Autogenous demineralized dentin matrix for tissue engineering applications: radiographic and histomorphometric studies. Int J Oral Maxillofac Implants. 2002;17(4):488-97.

7. Simion M, Baldoni M, Rossi P, Zaffe D. A comparative study of the effectiveness of e-PTFE membranes with and without early exposure during the healing period. Int J Periodontics Restorative Dent. 1994;14(2):166-80.
8. Carvalho VA, Tosello D de O, Salgado MA, Gomes MF. Histomorphometric analysis of homogenous demineralized dentin matrix as osteopromotive material in rabbit mandibles. Int J Oral Maxillofac Implants. 2004;19(5):679-86.

9. Grandini SA. The effect of partial-pancreatectomy-induced diabetes on wound healing subsequent to tooth extraction: histologic study in rats. Oral Surg Oral Med Oral Pathol. 1978;45(2):190-9.

10. Gerritsen M, Lutterman JA, Jansen JA. Wound healing around bone-anchored percutaneous devices in experimental diabetes mellitus. Biomed Mater Res. 2000;53(6):702-9.

11. Alkan A, Erdem E, Gunhan O, Karasu C. Histomorphometric evaluation of the effect of doxycycline on the healing of bone defects in experimental diabetes mellitus: a pilot study. J Oral Maxillofac Surg. 2002;60(8):898-904.

12. He H, Liu R, Desta T, Leone C, Gerstenfeld LC, Graves DT. Diabetes causes decreased osteoclastogenesis, reduced bone formation, and enhanced apoptosis of osteoblastic cells in bacteria stimulated bone loss. Endocrinology. 2004;145(1):447-52. 